\section{LEGUMBRES: EL PAN DEL POBRE}

\author{
José Ignacio Cubero Salmerón \\ Universidad de Córdoba \\ ge1cusaj@uco.es
}

\section{LEGUMES, THE POORMAN'S BREAD}

Cómo citar este artículo/Citation: Cubero Salmerón, J. I. (2016). Legumbres: el pan del pobre. Arbor, 192 (779): a312. doi: http:// dx.doi.org/10.3989/arbor.2016.779n3002

Recibido: 08 marzo 2016. Aceptado: 06 mayo 2016.
Copyright: (c) 2016 CSIC. Este es un artículo de acceso abierto distribuido bajo los términos de la licencia Creative Commons Attribution (CC BY) España 3.0.
RESUMEN: Domesticadas a la par que los primeros cereales y otros cultivos ricos en carbohidratos, compañeras inseparables de ellos en la tierra, en las costumbres, en la mesa y en el pesebre, en la agricultura moderna las leguminosas no son, sin embargo, más que secundarias o terciarias, a pesar de las llamadas a su consumo en dietas equilibradas y a la necesidad de su inclusión en la "alimentación" del suelo, es decir, en las rotaciones que incrementen la fertilidad del mismo de forma natural. Su riqueza en proteínas hizo que se llamaran "el pan del pobre"; su capacidad de fertilizar la tierra fijando nitrógeno atmosférico fue recomendación constante de los autores agrícolas desde los tiempos de Grecia y Roma. En el presente artículo se presentan las leguminosas no en sus aspectos técnicos sino en su relación con el Hombre desde diversos puntos de vista, incluyendo el papel que han representado en la Historia de la Ciencia al haber sido protagonista de estudios trascendentales como los de Mendel, Galton y Johannsen y la descripción del primer QTL entre otros.

PALABRAS CLAVE: Leguminosas; botánica; alimentación; cocina; folclore; genética.
ABSTRACT: Domesticated at the same time as the first cereals and other carbohydrate-rich crops, legumes have maintained close ties with these in all aspects of human life: in the land, traditions, and as food for man or animal feed. However, in modern farming they are only considered to be second class crops, in spite of continuous calls for their use in balanced diets and in crop rotations to increase soil fertility by fixing atmospheric nitrogen, avoiding excess use of synthetic fertilizers. Because of their high protein content they were known as "the poorman's meat". Moreover, their ability to fertilize soil was greatly valued by ancient agronomists since Greek and Roman times. Rather than focusing on the technical aspects of legumes, the present article considers the relationship between man and legumes from different perspectives, including their role in the History of Science, being protagonists of fundamental studies such as those carried out by Mendel, Galton and Johannsen, as well as the first description of a QTL. 


\section{UNA FAMILIA NUMEROSA}

La familia a la que pertenecen las especies aquí tratadas ha recibido al menos tres bien conocidos nombres desde que la Botánica estableció reglas taxonómicas firmes: leguminosas, papilionáceas y fabáceas. El primero responde a legumen, el nombre latino de los frutos (vainas) característicos de la familia, según Varrón derivado de legere, "arrancar", pues se cosechaban no segando como los cereales sino arrancando a mano las plantas; el segundo se debe al de su también característica flor, cuya forma recuerda la de una mariposa (papilio), y el último a una de sus especies, las habas $(f a b a)$.

Los dos primeros se encuentran en la literatura en igualdad de proporciones, el tercero responde al nombre botánico oficial, siendo una singularidad. En efecto, la taxonomía botánica moderna da a las familias nombres derivados de uno de sus géneros más típicos. Así, se prefiere poáceas (de Poa) a gramíneas, o brasicáceas (de Brassica) a crucíferas, etc., pero el género Faba no existe en la actualidad, aunque sí lo hizo mucho tiempo atrás, cuando a las habas se las denominaba Faba bona por botánicos del XVIII siguiendo a Medikus, que les dio tal nombre en 1787 . Fue Linneo quien, en 1753 , les dio el nombre de Vicia faba que ha prevalecido a pesar de las numerosas dudas que siempre han existido en cuanto a su grado de parentesco, es decir, en cuanto a proximidad real, con el resto de especies del género Vicia; el hecho de contener doble cantidad de ADN que el resto de congéneres y la estructura de sus cromosomas añade peso sustancial a las dudas meramente morfológicas. Es cierto que la domesticación pudo jugar un papel esencial en esta diferenciación. En todo caso, el apunte es puramente botánico respecto a la curiosidad de que el nombre de la familia no tenga un género en el que repose (Polhill y Raven, 1981).

Es una familia enorme; con más de 20.000 especies es una de las mayores de la Botánica, a pesar de lo cual ha sido relativamente poco explotada por los agricultores, si bien una gran cantidad de ellas ha sido utilizada por cazadores-recolectores por sus frutos, semillas e incluso hojas y tubérculos, y asimismo por pueblos ganaderos, pues los pastizales favoritos son los que se basan fundamentalmente en una buena proporción de gramíneas y de leguminosas. Es la teoría del equilibrio llevada a la práctica.
En efecto, las fuentes primarias de hidratos de carbono (cereales en zonas templadas, tubérculos y raíces en las tropicales) han tenido en todas las culturas unas compañeras inseparables: las leguminosas. Se complementan en la dieta tanto en las proporciones de proteínas e hidratos de carbono como en las carencias respectivas en aminoácidos esenciales. No es extraño, pues, que en grandes regiones del mundo se viva a base de comer diariamente arroz con judías, sémola de trigo con garbanzos, etc. La asociación va más allá de lo nutritivo, puesto que se complementan también en la extracción de nutrientes $y$, además, a causa de la simbiosis existente entre leguminosas y bacterias fijadoras de nitrógeno atmosférico, constituyen una rotación perfecta.

\section{LA CARNE DEL POBRE}

No es por azar que la asociación cereal (o productor de hidratos de carbono)-leguminosa esté presente en todas las regiones del mundo desde el origen de la Agricultura: en el Próximo Oriente y regiones bajo su influencia, trigo y cebada con habas, garbanzos, lentejas, guisantes etc.; en África, sorgo y mijo con la judía carilla (de origen africano; véase la última sección de este artículo en relación con este nombre); en América, maíz con varios frijoles americanos; en el norte de China, mijos y soja (hoy oleaginosa, entonces fuente de proteína y grasa) y, en general, en todo el Lejano Oriente tropical, arroz con varias judías asiáticas, parientes tanto de las africanas como de las americanas. En otras regiones donde no era posible el cultivo de grano, las leguminosas acompañaron plantas suministradoras de azúcares: en el altiplano andino, el altramuz tarwi a la patata, en los trópicos polinésicos varias judías al sagú o a la batata, en África tropical a los ñames o, más tarde, a la mandioca. Se comprende fácilmente que la gran cultura vegetariana, la hinduista, haya basado su cocina milenaria en un equilibrio dietético en el que las leguminosas juegan un papel esencial. Son, pues, no solo "carne del pobre" sino también "carne del vegetariano".

Nada mejor que reproducir un ya comentado pasaje del Libro de Buen Amor para mostrar su papel de "carne", en este caso para una dieta vegetariana obligada. Le dice Doña Cuaresma a Don Carnal, tras haberlo vencido en singular combate: 
El día de domingo, por tu codicia mortal

comerás garbanzos cochos con aceite y no ál;

$\cdots$

En el día del lunes, por tu soberbia mucha

Comerás de las arvejas, más no salmón ni trucha;

$\cdots$

El jueves cenarás, por la tu mortal ira

Y porque perjuraste diciendo mentira

Lentejas con la sal: en rezar te remira;

Cuando mejor te sepan, por Dios de ti las tira.

$\cdots$

Come el día del sábado las habas y no más:

por tu envidia mucha, pescado no comerás...

etc. etc.

Teniendo en cuenta que, además, Don Carnal tenía que comer gachas (en la cual entrarían las almortas) los martes, la proporción de leguminosas en su dieta es verdaderamente notable. Dieta, en su caso, de penitencia, pues Don Carnal era rico: "carne de vegetariano" (hoy en día, de dieta de adelgazamiento, otra especie de penitencia); para los no privilegiados, vegetarianos obligados, garbanzos, habas, lentejas, guisantes (las arvejas del Arcipreste, hoy el nombre común en América) y almortas eran la "carne del pobre", pero con ella crecían sanos y fuertes.

Aunque en épocas recientes el aceite ocupe el primer lugar en algunas especies (soja, cacahuete) es la proteína, la que confiere la categoría de "carne". El porcentaje medio de proteína en la semilla madura se sitúa, en general, entre el 20 y $25 \%$, pudiendo aumentar con relativa facilidad por selección, pero los altramuces sobrepasan el $30 \%$, incluso sin haber sido seleccionados para ello (y el amarillo rebasa el $40 \%$ ); soja y cacahuete, después de haber sufrido una extraordinaria labor de selección, superan el 35\% el primero y el $25 \%$ el segundo, aun cuando la selección fue realizada para incrementar la proporción de grasa (Pérez de la Vega, Torres, Cubero y Kole, 2012).

Un punto débil es el bajo contenido en aminoácidos azufrados de esa proteína. Sin embargo, en la práctica esto no es importante pues nunca figuran en solitario en la dieta o en los piensos; sus eternos compañeros en ambos casos, los cereales, compensan ese déficit y, a su vez, ven compensado su bajo contenido en lisina, que le sobra a las leguminosas. Es esa combinación la que permite una dieta equilibrada (aparte de las adiciones industriales de aminoácidos sintéticos). De ahí que los platos compuestos con arroz y judías sigan siendo la comida diaria en grandes regiones del mundo, como también los "potajes" mediterráneos y otros platos semejantes ("cocido", cuscús, etc.) (Cubero y Moreno, 1983).

\section{ALGUNOS INCONVENIENTES}

El punto verdaderamente débil no es ese, sino la presencia de elementos no nutritivos, algunos de los cuales son manifiestamente tóxicos. La variedad es enorme. Hay factores latíricos, cianogénicos, antitrípsicos, alcaloides, aminoácidos no proteicos, etc.; otros son simplemente molestos (digestiones pesadas) o inocuos aunque socialmente inconvenientes, como los causantes de flatulencia. Huelga decir que todas las plantas, en su estado natural, es decir, sin haber sufrido un proceso de selección, tienen factores de ese estilo, y la razón es sencilla: atacada por un predador, la planta no puede huir como lo hace un animal, pero ha de defenderse, y lo hace con espinas, vellosidades, glándulas diversas... y con sustancias tóxicas acompañadas de sabores amargos que le indican al predador "cuidado... que debajo hay un veneno..." (Font Quer, 1962). Una planta que ofrece una buena proporción de proteína (y de hidratos de carbono) sería un bocado exquisito a no ser por esas defensas.

No debe exagerarse, en general, la presencia de tales elementos, pues de nuevo hay que decir lo mismo que lo indicado respecto al bajo contenido en aminoácidos azufrados: las leguminosas no son nunca un alimento que se de en estado puro sino en mezcla, por lo que la proporción de sustancias antinutritivas disminuye por debajo de valores umbral. Además, la selección intuitiva, más bien automática, ha hecho que se fuesen seleccionando variedades con menor contenido en estas sustancias; lógicamente, ante un altramuz amargo y uno dulce nos quedaremos con el dulce, que sembraremos y multiplicaremos.

En todo caso, es notable cómo el Hombre ha sido capaz de salvar este inconveniente en su dieta, eliminando o reduciendo su contenido hasta niveles tolerables. El simple "remojado" aumenta la digestibilidad, la cocción suele eliminar mu- 
chos de estos factores; por ejemplo, los principios cianogénicos (productores nada menos que de cianuros) presentes en las judías se eliminan cociéndolas, pero dicha operación está restringida a la preparación de alimentos para el hombre, no de piensos. Hay procedimientos industriales que lo consiguen, como es el caso de la soja, una de las que mayor número de factores antinutritivos posee $y$, sin embargo, tras la extracción de aceite, su torta extrusionada está completamente limpia de los mismos. Otros se eliminan con el lavado, como, por ejemplo, los alcaloides (que producen sabor amargo pero que pueden llegar a ser tóxicos) de los altramuces: ha sido práctica habitual de los ganaderos la de sumergirlos durante varios días en un arroyo, en alguna acequia o en algún pilón en el que se mantenga una corriente de agua, y recuérdese cómo se consumen como aperitivo: embebidos en agua salada. En suma, entre el lavado y la cocción, dos procedimientos culinarios ancestrales, se logra una buena eliminación, y la no menos ancestral mezcla con otras materias (cereales, verduras, etc.) rebaja aún más el contenido en sustancias no nutritivas (Nadal, Moreno y Cubero, 2004).

Algunos de esos factores merecen un comentario especial, pues no todos se eliminan por procedimientos sencillos como el lavado o la cocción. Las especies del género Lathyrus, conocidas como almortas y titarros, contienen un aminoácido libre (pseudoleucina) pero que, al ser muy similar a la leucina, puede integrarse en las cadenas peptídicas produciendo proteínas tóxicas que pueden hacer degenerar la médula espinal provocando parálisis parcial o total. La harina de almortas ha sido sin duda con la que mejores gachas se han cocinado en España, a pesar de lo cual no ha habido problemas ya que para sufrir tal enfermedad, latirismo, hay que consumir grandes cantidades de forma continua durante un largo tiempo, lo que solo ha sucedido en circunstancias especiales de hambrunas terribles, como en India tras la segunda guerra mundial por ejemplo: las almortas llegaron a constituir el componente principal de la dieta (son un cultivo enormemente resistente a circunstancias adversas, algo que los agricultores sabían), y las consecuencias fueron nefastas. En fechas más cercanas se han dado casos de latirismo al consumir veza en lugar de lentejas (de Haro, 1983). Como la pseudo-leucina y otros aminoácidos análogos son resistentes a todo tratamiento industrial, solo cabe la mejora genética para solucionar el problema.

Otro caso interesante es el del fabismo, nombre evidentemente derivado de "faba". Es más complicado, pues, a diferencia del anterior, la consecuencia de la ingesta de habas (sobre todo inmaduras) depende de que el consumidor posea un determinado gen que le hace ser sensible a algunas moléculas pequeñas (las dos principales llevan los nombres de vicina y convicina) e indestructibles por cualquier procedimiento: solo las elimina la selección genética. El fabismo consiste en una hemorragia estomacal que puede ser grave en regiones con pobres recursos hospitalarios. El fabismo no es una reacción alérgica, en contra de una opinión muy extendida; es una reacción fisiológica que necesita una constitución genética y un estímulo producido por las habas (de Haro, 1983; Pérez de la Vega et al., 2012). ¿Cómo se ha mantenido ese gen en las poblaciones humanas siendo, como es, francamente deletéreo...? En principio debería haber desaparecido, o al menos estar en muy baja frecuencia, por selección natural. Si no es así, como es demostrable en poblaciones mediterráneas, ha de ser porque debe reportar alguna ventaja. En este caso, se ha sugerido un efecto de resistencia o tolerancia a alguna enfermedad endémica (por ejemplo, la malaria) en la misma zona en que se registra el fabismo; por alguna razón, los portadores de esos genes la toleran mejor que los no que no lo tienen en su constitución genética (Pérez de la Vega et al., 2012). Toda moneda tiene dos caras... Como consejo práctico, lector, si usted ha consumido habas en cualquier forma y no ha tenido nada, puede comer todas las que quiera; y si ha tenido alguna hemorragia, no las consuma más, pero no busque vacunas: el problema está en sus genes y no se le pueden quitar. En cambio, las sustancias productoras de fabismo sí se le pueden quitar a las habas por selección, y hay variedades que no las tienen.

Los dos casos anteriores son dignos de mención pero el lector no debe pensar que es algo general en las leguminosas; como alimentos valiosos que son, se han protegido con multitud de defensas, pero ya se ha dicho que no siendo componentes únicos de la dieta, los efectos nocivos son raros. No solo eso; es poco sabido que algunos granos naturales, sin tratamientos, como el garbanzo o la lenteja que se consumen 
en nuestro país, de colores claros, muestran valores biológicos comparables al de la torta de soja tratada por procedimientos industriales. Y los de negros o muy oscuros, ricos en sustancias que dificultan la digestión, que son los que se consumen en el subcontinente indio (donde la lenteja es elemento fundamental en la cocina), no ocasionan nada porque se los ha consumido descascarillados desde tiempo inmemorial... ¿Por qué esa diferencia de colores en India y en el Mediterráneo...? Selección intuitiva en este y culinaria en aquel... Primitivos, sí, pero no ignorantes. De ahí que existan variedades de altramuces sin alcaloides, sin taninos en habas, guisantes, garbanzos, judías, etc. Los casos más difíciles (fabismo, latirismo) han requerido la acción de la moderna Mejora genética una vez conocidas las sutiles causas que los provocan.

\section{EL PAN DEL POBRE EN SU COMIDA Y SUS COSTUMBRES}

Siempre tuvieron fama de digestiones pesadas, y es cierto: fuertes cutículas con abundantes taninos (salvo las que a lo largo de siglos, y también en nuestros días, se seleccionaron de flor blanca o colores claros de grano) no pueden producir otra cosa. Algunos otros de los factores señalados más arriba, como los de flatulencia por ejemplo, colaboran en el resultado. De ahí que, para aliviar la digestión y aumentar su valor biológico, haya que cocerlas o descascarillarlas o ambas cosas; se lee, en efecto, en Al Awam: "El más seguro modo de cocer las habas y toda especie de legumbres es cocer sola el agua hasta que dé tres o más hervores, y después echar en ella las habas bien limpias de su cáscara, y lo mismo las demás legumbres; lo cual acelera su cocimiento". Hay que tener en cuenta que los potajes y cocidos se han acompañado de todo lo que se ha podido: verduras, cereales, carnes recias de difícil masticación, huesos y tocinos rancios... no eran los mejores acompañantes para una sobremesa apacible. Sorprende, sin embargo, la opinión de un autor antiguo y respetable de que los garbanzos estimulan el apetito sexual... Es más lógico lo que se dice de las habas: "Los filósofos de la naturaleza dicen que las habas embotan el corazón de los que las comen; por eso creen que también estorban los sueños verídicos..." (Cubero, 2016).

Como todos los demás granos, los de leguminosas, descascarillados o no, se molían y mez- claban con otros para formar una masa base de pan (realmente, tortas) auténticamente "integral", enriquecido con proteínas que complementaban las de los cereales en el contenido en aminoácidos. Ese es el pan que se sigue haciendo en la cocina india, que utiliza para ello sobre todo lentejas, pero antiguamente los panes de garbanzos, habas y de cualquier otra leguminosa (incluso de altramuces tras lavarlos para eliminar el amargor) eran conocidos en todas partes, con frecuentes alusiones a digestiones lentas pues en las recetas que a veces dan se añade, además de carne si se puede, "cebolla, aceite, manteca, y queso seco..." y además, por si fuera poco, "cuyo pan se come con grosuras, mantecas, aceites y carne gorda, habiendo mezclado con su masa lo que dijimos se mezclase con la del panizo y del mijo" (Cubero, 2016). Un buen alimento, sin duda, pero...

En la manera más general de potajes y gachas (la de almortas es exquisita) hay que decir que, si bien en nuestra sociedad son ya platos de restaurante, en algunos lugares siguen siendo comida básica y a veces única: arroz con frijoles en buena parte de América central, "ful madamas" en Egipto, cuscús en el Magreb, etc. En nuestro país siguen siendo enormemente populares las judías (con toda variedad de nombres) con chorizo, fabadas, lentejas, sin olvidar al cocido de garbanzos en sus múltiples facetas: madrileño, con callos, de vigilia, etc.... Y quien haya pasado en Inglaterra siquiera una noche no habrá dejado de tomar, ide desayuno...!, judías estofadas...

La buena mesa exigió productos más delicados que el grano seco. Entre las judías se seleccionaron algunas variedades para su consumo como grano tierno, inmaduro pero no verde (ha de clavársele la uña): las "pochas". Como aperitivos se toman así habas en algunas regiones, pero lo común es consumir el grano verde, inmaduro, de habas (las "baby" se han impuesto en el mercado) y guisantes (los impuso Luis XIV y los nobles franceses lo siguieron, lógicamente), tanto en fresco como, cada vez más, procesado, algo que también se hace con grano seco de garbanzos, lentejas y judías (y pochas) ofreciéndose hoy una oferta de cuarta y quinta gama inmejorable.

En la antigüedad se le atribuyeron algunas propiedades curiosas, además de la afrodisiaca del garbanzo mencionada más arriba. Esos mismos garbanzos "comidos calientes o fríos alegran al 
que los comiere, divierten el ánimo, hacen olvidar los cuidados, fortalecen el corazón, y apartan los pensamientos sombríos" y también "las lentejas egipcias deparan alegría a los que las comen", algo en lo que debía penar también los romanos, pues por algo debió escribir Virgilio "no olvidéis las lentejas de Pelusium", la ciudad del Delta egipcio famosa por sus productos agrícolas. Y, desde luego, alegraron al Patriarca Jacob tras prepararle un plato de lentejas a su hermano Esaú con el que le arrebató, de forma poco ortodoxa, la primogenitura. Menos satisfacción le debió dar a Colón encontrar, en el puñado de garbanzos que sirvió para echar suertes, en medio de una tremenda tormenta a la vuelta del primer viaje, uno negro: eso quería decir que, si se salvaban, tendría que ir a Guadalupe en peregrinación. El garbanzo negro le tocó a él, pero nunca fue (Cubero, 2016).

Por su parte, las habas "quitan de la boca el olor del ajo comidas inmediatamente después", algo que, al igual que la naturaleza afrodisiaca del garbanzo, no es aconsejable poner en práctica. Tampoco la de quitar de los vestidos las manchas de sangre lavándolos con garbanzos molidos y mezclados con jabón o sal... Y quedan en el folclore popular multitud de expresiones: "lentejas... si quieres las comes y si no las dejas", es decir, "esto es lo que hay..." "El garbanzo negro de la familia" se sigue diciendo aunque ya no se encuentran ni en el mercado ni en el cultivo garbanzos negros mezclados con los de color "garbanzo" (es una categoría propia). En el clásico roscón de Reyes, lo tradicional era colocar, en lugar de las figuritas de plástico actuales, granos de habas ("las habitas de la suerte"), tradición quizá relacionada con la de "echar las habas" como medio de adivinación, a la manera de los palillos de madera o hueso en otras culturas. Muestra de su consumo, y no precisamente por potentados económicos, son expresiones tales como "en todas partes cuecen habas", "son habas contadas", "tonto del haba" ("estar faba" dicen los valencianos), "me importa un haba", y otras con referencias anatómicas no apropiadas en este lugar.

\section{EL “PAN” DEL SUELO DEL POBRE}

Símaco, vástago de una importante familia senatorial romana del siglo IV dC, visitaba sus inmensas propiedades y le da cuenta a su padre de la inspección:
"Nuestro patrimonio familiar decae y debemos examinarlo continuamente... pues sucede en nuestra época que el campo, que solía dar alimento, debe ser alimentado".

Es difícil hallar una mejor descripción de un eterno problema: el de la pérdida de fertilidad del suelo agrícola con un cultivo incesante (Cubero, 2016). La primera intuición de que la tierra perdía poder estuvo ya en la mente de los primeros cultivadores que practicaron la roza. Al cabo de pocos años, debían abandonar la parcela desmontada y cultivada porque ya no daba más. Hay que reponer lo que se saca, y reponerlo equilibradamente para reconstituir el suelo en sus propiedades físicas, tan importantes como las químicas. Entre las soluciones están dar descanso a la tierra uno o varios años, esto es, dejarla en barbecho, o bien, si hay suficiente tierra inculta, practicar la agricultura itinerante. Otra solución es abonar, pero durante miles de años el único abono fue el estiércol y su utilización dependía del manejo del ganado (se pierde en la trashumancia, por ejemplo) y del propio manejo del estiércol: no debe ser fresco sino maduro, para lo cual se debe tener un estercolero para el primero y otro para el segundo.

Ahora bien, la fertilidad se puede reponer por medio del cultivo de leguminosas pues tienen la peculiaridad de fijar nitrógeno atmosférico en forma de fertilizante gracias a las bacterias del género Rhizobium y relacionados que viven en simbiosis en sus raíces con beneficio mutuo para huésped y bacteria: esta desarrolla su ciclo englobada en unos nódulos que forman las raíces y recibe un buen suministro de azúcares y de otras sustancias que necesita, y la planta consigue una buena dosis de nitrógeno, esencial para la síntesis de todo tipo de proteínas. La razón de este suministro se debe a la peculiaridad de esas bacterias de poder fijar el nitrógeno atmosférico (químicamente inerte) en forma de compuesto amoniacal que se une a los ácidos orgánicos para formar aminoácidos, los "ladrillos" de las proteínas. Como "subproducto", el exceso de nitrógeno atmosférico fijado en las raíces en moléculas de amonio por los nódulos bacterianos queda en el terreno, enriqueciéndolo así en un bien escaso. No todas lo hacen igual, sin embargo, porque la asociación entre huésped y simbionte a veces es muy específica. Por eso hay que tener cuidado cuando se 
transfiere un cultivo de leguminosa a una región donde nunca se la conoció, a menos que se lleve con ella la bacteria (en tiempos antiguos como impurezas de tierra en los sacos de transporte, hoy en forma de productos industriales) y que esta colonice los nuevos territorios. Es el caso, por ejemplo, de la soja fuera del norte de China o de las nuevas forrajeras africanas en América (Cubero y Moreno, 1983).

La base científica de esa simbiosis no se conoció hasta finales del siglo XIX pero sus efectos se sabían desde tiempos remotos. Los autores griegos y romanos, en efecto, reconocieron que los cultivos de habas, lentejas, guisantes, etc., "estercolaban" la tierra y recomendaron su alternancia con cereales, lo cual era, dicho sea de paso, una práctica común en las agriculturas de todo el mundo, que en lugar de las mencionadas leguminosas mediterráneas utilizaban las autóctonas. Es una manera fácil y eficaz de mantener la fertilidad del suelo.

No es por azar que todas las agriculturas iniciales domesticaran cereales y leguminosas: en el Próximo Oriente, trigo y cebada con guisantes, yeros, garbanzos y habas; en África, sorgo y mijos con la judía carilla entre otras. En Asia, junto al mijo en el norte y al arroz en el sur surgen soja y varias judías bien adaptadas a sus ambientes. En las dos Américas, maíz y judías (distintas, pero emparentadas, en el norte y en el sur); la legendaria triada de las "Tres Hermanas" de la primera agricultura americana: maíz, judía y calabaza motivó no pocos cuentos y leyendas entre las tribus primitivas. Hoy se siguen reconociendo los méritos de la asociación y de las rotaciones para lo que se llama "agricultura sostenible", pero con escaso éxito: el monocultivo feroz es el que domina el mundo desarrollado a pesar de los numerosos estudios que muestran que una simple alternancia de, por ejemplo, trigo con guisantes o habas produce más que el monocultivo continuado de trigo... pero es inútil, pues las cuentas no se hacen a plazo medio o largo sino al final de la campaña, olvidando que, a pesar de los abonos de síntesis, el suelo degenera, pues el suelo no es algo inerte sino un organismo vivo repleto de micro y macroorganismos necesarios todos ellos para mantenerlo vivo. No en vano, cereales y leguminosas constituyen la base de todos los prados y estepas naturales en todo el mundo.

\section{PAN Y ESPÍRITU}

El cereal, como alimento principal del Hombre en casi todas las regiones geográficas, siempre ha tenido connotaciones religiosas; su cultivo ha sido enseñado por los dioses y con frecuencia el dios se ha encarnado en él; baste recordar trigo (hasta hoy en día en la misa católica), cebada y maíz, en distintas religiones sin conexión entre sí. Las leguminosas no han tenido esa consideración como simples acompañantes del alimento básico que son, pero un caso al menos nos muestra que también fueron compañeras en este papel.

Las habas estuvieron prohibidas para los sacerdotes en el Antiguo Egipto, según cuenta Heródoto, algo que se ha atribuido al fabismo ya comentado. Como todo lo relativo a las prohibiciones y tabúes, incluyendo los del cerdo y la vaca sagrada india, hay que pensar más bien en alguna relación con potencias ajenas al Hombre cuyo sentido se ha perdido. En el caso del cerdo y de la vaca india ha habido excelentes estudios que muestran el sentido de esos tabúes; en el cerdo, por ejemplo, los partidarios de la triquina se olvidan de que la porcofilia estuvo, y está, infinitamente más extendida que la porcofobia, con la triquina presente en todos sitios por igual, y también olvidan que el cerdo era el animal nada menos que de Deméter y esencial en sacrificios y ritos romanos y griegos (su sangre servía... ipara purificar las asambleas...!) (Cubero, 2016; Darby, Ghalioungui y Grivetti, 1977).

No hay tantos estudios en el caso de las habas. Que hay algo subyacente es obvio, porque las habas se consumían por la población laica egipcia que, lógicamente, debía presentar tanta frecuencia de fabismo como la casta sacerdotal. Se dice que Pitágoras, educado con sacerdotes egipcios, mantenía que estaban hechas de la misma naturaleza que el hombre y se negaba a comerlas, algo que también se encuentra en un verso atribuido a Orfeo: "Comer habas y la cabeza de los padres es lo mismo en verdad". Fiel a su creencia, huyendo Pitágoras de los tarentinos, por no cruzar en su huida un campo de habas fue apresado y muerto. Se lee asimismo en la Geopónica de Casiano Baso que Pitágoras decía que no se debían comer habas "porque hasta en su flor se encuentran signos funestos" (Darby et al., 1977), algo de lo que no participaron los poetas hispano-musulmanes cuando comparaban las flores puntuadas de negro con "un lunar en la mejilla" de la amada (Cubero, 2016). 
Recuérdese que, en Roma, entre la más rancia nobleza de la Roma primitiva figuraba la gens Fabia. Eran las habas, además, protagonistas del muy antiguo festival romano de las Fabaria, relacionado primitivamente con el culto a los antepasados, aunque se ha perdido el sentido de su origen, así como el rito de arrojar, durante el festival, un grano de haba por encima del hombro. Se celebraban en el 1 de junio en honor de la diosa Carna, a la que se le ofrecían tortas de harina de habas con manteca.

\section{CUESTIÓN DE NOMBRES: JUDÍAS, FRIJOLES, ALUBIAS,} CHÍCHAROS, HABICHUELAS...

Típico caso de domesticación simultánea e independiente en multitud de lugares debido a su buen contenido en proteínas, este importante grupo de leguminosas de grano está constituido por no pocas especies pertenecientes a varios géneros muy emparentados entre sí y a veces de difícil distinción incluso por botánicos avezados. De ahí la multitud de sinonimias y de vacilaciones taxonómicas y su confusión en la cocina, pues todas ellas conocen usos comunes. Su historia y la de sus nombres merecen un comentario especial.

En África occidental se domesticaron algunas de estas leguminosas, particularmente las hoy clasificadas como Dolichos lablab y Vigna unguiculata, compañeras del sorgo y de los mijos; no tuvieron éxito al norte del Sahara, pues siendo plantas de día corto había que sembrarlas en nuestra primavera para que se desarrollaran en nuestro verano y se recogieran en nuestro otoño, es decir, en nuestra estación seca cuando en su región de origen lo hacen en la húmeda. En el verano mediterráneo necesitaban riego, y de ahí que los tratadistas grecorromanos le tuvieran a estos cultivos tan poca simpatía. Los griegos las llamaron faseol y los romanos faseolus. Más tarde, los árabes las denominaron lubia y, por la fuerte influencia griega que siempre hubo en Egipto desde los Ptolomeos, fasulia. Eran muy parecidas en formas, cultivo y usos, y los nombres, con toda probabilidad, se aplicaban a ambas especies. De ellos se derivan los españoles fasol, frejol, frijolfrijol y otros similares, y, evidentemente, alubia. Los primeros persistieron en Castilla, "alubia" en lo que había sido musulmán. Es posible que, por semejanza con las vainas y granos de habas, se conocieran ya como habichuelas ("habicholillas", sin diptongo, en varios lugares andaluces).
En Oriente se domesticaron también una buena cantidad de especies similares a las africanas, con los mismos tipos de cultivo y uso, que hoy reciben el nombre genérico de "judía" con algún determinativo (judía mungo, adzuki, alada, de sable, etc.) Además, el frijol africano, tras pasar por la Ruta Sabea a India y luego hasta Indonesia, se diversificó tanto que hizo pensar a buenos botánicos en su posible origen asiático; no es así, pero la diferenciación fue enorme, y parte de esas variedades volvieron a Europa por el Corredor Árabe.

En América existía una gran cantidad de especies estrechamente emparentadas con las anteriores, de las que se domesticaron varias, alguna hace al menos 7000 años, desde Mesoamérica hasta el norte argentino. Como las africanas, su ciclo se desarrolla en nuestro verano. En una zona de domesticación tan extensa, las distintas especies (Phaseolus vulgaris, lunatus, acutifolius, coccineus) recibieron diversos nombres (poroto, pallar, tepari, escomite, ayacote, acalate...) que llegan a nuestros días. Su parecido en todo es tan grande con las que entonces existían en el Antiguo Mundo que los primeros españoles que pisaron el Nuevo no dudaron en darles el nombre castellano: frijoles.

Pero en tanto que el frijol conocido en España no se extendió grandemente por el Nuevo, sucedió al revés en dirección contraria. De más calidad y mayor producción, con mucha mayor variación, terminaron por desplazar a las existentes y adoptar sus nombres: frijol, alubia, habichuela..., tomando, además, otros en distintas regiones y a veces para distintas especies como garrofón o habón (para la judía de Lima en Valencia), fabes (en Asturias), caparrón (de grano rojo, en La Rioja), etc. El primitivo frijol de remoto origen africano hubo de adoptar otros nombres: judía carilla o de careta, frijol de carita, etc., por la manchita que tienen en torno al hilo de la semilla (que, por cierto, también tienen muchas variedades de frijoles americanos) (Un inciso: el nombre más extendido hoy en día para la alubia o judía antigua, incluso en autores españoles que ignoran la historia, es caupí, pura transcripción del nombre inglés cow pea, sin que tenga nada que ver ni con "vaca" ni con "guisante"). Para aumentar la confusión, también se conocen todas ellas en algunos lugares como chícharos (sobre todo para variedades de grano blanco de 
la judía común) nombre verosímilmente derivado del latino cicer (garbanzo) o del italiano cicércula (almorta) sin que tenga mucha relación con ninguno de estos dos cultivos, pero sí en el uso culinario, que es lo que le importaba a las clases humildes en la antigüedad.

El "trasplante" de nombres populares también ocurrió en inglés: bean era el nombre genérico para las habas, y así llega hasta el siglo XIX según los diccionarios y textos agrícolas de la época; las judías, por su forma también arriñonada, se denominaban con esa palabra y determinantes variados: common bean, french bean, kidney bean, etc. Hoy sucede al revés: "bean" refiere indefectiblemente a la judía, y son las habas las que se denominan faba bean, horse bean, etc. Más sorprendente resulta el hecho de que el trasplante de nombres también terminó ocurriendo en los científicos. Casi todas las especies anteriores, tanto del Viejo como del Nuevo Mundo, se clasificaron en el género Phaseolus, derivado del primitivo nombre latino. Avanzado el siglo XX se pensó que convenía dividirlo para una mayor precisión taxonómica. La idea inicial de dividirlo en dos géneros principales, Phaseolus y Vigna, atendiendo a las especies del Nuevo y del Viejo Mundo respectivamente, nunca se pudo completar a la perfección, pero como resultado, el venerable nombre grecolatino y aun árabe, faseolus-fasulia, se le otorgó ia las especies americanas...! Vigna fue el que recibieron la mayor parte de las afroasiáticas, pero quedan reductos de Vigna en América y de Phaseolus en Asia. Junto a ellos se conservan Dolichos, Canavalia, Psophocarpus y algunos otros.

¿Y el nombre judía, el más común en España para todo este conjunto de cultivos...? Pues no se sabe a ciencia cierta nada sobre su origen. Todos los autores, hasta ahora y salvo alguna opinión delirante, están de acuerdo en que no tiene nada que ver con los judíos. Aparece en el siglo XVII, pero se populariza en el XVIII y desplaza a los demás, sobre todo al antiguo "frijol" que queda, en la mente popular, como típicamente americano siendo el de más reciedumbre castellana. La palabra judihuela, que se lee en algún autor del XVII como el Padre Cobo (en América) y Fray Miguel de Agustín ("El Prior") en España, le ha sugerido a algunos una corrupción a partir de habichuela en ambientes moriscos, pero el juego malabar que hay que hacer para demostrarlo tiene más de ficción que de certeza.
Claro que el nombre español de "garbanzo" no se sabe de dónde viene; ciertamente, ni de las lenguas indoeuropeas ni del vasco. ¿Y qué hay de la indudable conexión entre "lente" (ocular) y "lenteja"...? En latín ambas son lens, pero es un caso de huevo y gallina: los lingüistas no se deciden sobre cuál deriva de cuál, pero para los agrónomos, como el que suscribe, está claro: la "lenteja" es natural, le lente óptica no. Cuál sea el origen de la natural, es otra cosa (Cubero, 2016).

\section{PAN DE LA CIENCIA}

No sería justo terminar estas notas sin mencionar el papel desempeñado por las leguminosas en la Historia de la Ciencia. Pasemos por alto el estudio del tactismo en la mimosa que, con razón, se la denominó Mimosa púdica por cerrar sus foliolos al menor roce de la mano (la mimosa auténtica, no las numerosas acacias que se suelen llamar así). Igualmente dejemos de lado los abundantes estudios sobre su taxonomía, su sistemática y su evolución, al ser una enorme familia tan diversa en todos sus aspectos formando, sin embargo, una unidad filogenética indudable demostrable asimismo desde todos los puntos de vista incluido el de la biología molecular (Polhill y Raven, 1981).

Se ha mencionado antes el papel de las leguminosas en la fertilización del suelo, algo que hizo que los antiguos dijeran que "estercolaban" el terreno. Hasta que no se pudo demostrar que el nitrógeno del aire se fija en el suelo en forma amoniacal por la acción de las bacterias que forman nódulos en las raíces de las leguminosas no se supo explicar tal peculiaridad ni zanjar el problema de la adquisición de nitrógeno por la planta. La demostración fue, en los años ochenta del XIX, química, por Hermann Hellriegel, y biológica, por Martinus Willem Beijerink, que aisló en 1888 el primer rizobio, Rhizobium leguminosarum, de los nódulos de las raíces de las leguminosas. El estudio del mecanismo de la nitrificación arranca con Sergei Nikolaevitch Winogradsky (1856-1946), el fundador de la microbiología del suelo (Cubero y Moreno, 1983; Nadal et al., 2004).

El sistema, como bien se sabe hoy, es complejísimo desde el punto de vista molecular: el huésped ha de poseer genes específicos para aceptar a la bacteria y la formación de nódulos que esta necesita para desarrollarse, la cual ha 
de disponer asimismo de genes para reconocer al huésped que la alberga; el nódulo crea el ambiente anaerobio obligatorio para los rizobios por medio de la leg-hemoglobina, otro fenómeno biológico al poseer secuencias de aminoácido idénticas a la hemoglobina de mamíferos (Orive y Temprano, 1983). Realmente, la que hoy parece una perfecta simbiosis debió comenzar como pura enfermedad bacteriana, y de hecho lo es pues la producción de la leguminosa se resiente, si bien se compensa con la mayor cantidad de proteínas que posee. La asociación no es consustancial con las leguminosas, pues no se da en las más primitivas (en casi todas las cesalpinoideas y en algunas mimosoideas); solo las faboideas la poseen íntegramente: claramente es una "infección" que se convirtió en asociación beneficiosa permanente (Cubero y Moreno, 1983).

No menos importante, quizá mucho más, es el papel desempeñado en el nacimiento de la Genética y, por supuesto, en el de la Mejora genética. En el siglo XVIII, las sociedades científicas de Inglaterra, Alemania y Francia ofrecieron premios a quien descubriera los principios de la herencia, lo que dio lugar a un trabajo de investigación de intensidad desconocida hasta entonces. El inglés Thomas Andrew Knight (1759-1838) y los franceses Augustin Sageret (1763-1851) y Charles Victor Naudin (18151899) estuvieron muy cerca de hacerlo, pero el mérito de haberlo conseguido recae en un modesto monje agustino, Gregor Mendel (18221884), en el convento de Brünn (hoy Brno) en Moravia (Blaringhem, 1919). Los conocidos trabajos de Mendel con guisantes, en los que utilizó rigurosa y magistralmente el método científico, le llevaron a enunciar sus "Leyes", comunicadas en la Sociedad de Historia natural local en 1865 y publicadas el año siguiente en sus Anales. Es suficientemente conocido que sus resultados pasaron desapercibidos hasta 1900 , año en el que tres científicos los "redescubrieron" (se sospecha fuertemente que, al menos dos de los tres, los conocían) y pudo iniciarse el explosivo desarrollo de la Genética y de sus aplicaciones, entre otras la selección de nuevas variedades con criterios sólidos (Srb, Owen y Edgar, 1968). Pero ¿por qué el guisante, humilde planta que hizo que Mendel fuera criticado en su tiempo, por no haber elegido las que los grandes científicos manejaban...? Muy posiblemente porque gracias a Luis XIV, que los adoraba en su mesa, se produjo una proliferación de variedades con formas y colores de todo tipo; es mérito de Mendel haber considerado que más valían esos caracteres sencillos (de los que también consta que los cribó para elegir los que le parecieron más convenientes) que los muy complicados tan del gusto de los grandes evolucionistas del XIX.

Al mismo tiempo que Mendel, pero en un ambiente radicalmente distinto, Sir Francis Galton (1822-1911), miembro de la alta clase intelectual y económica inglesa, realizaba sus trabajos en una especie ornamental intentando asimismo llegar a la base biológica de la herencia. Era una especie curiosamente pariente muy próxima del guisante de Mendel, el mal llamado "guisante de olor" pues no es un guisante ni tiene mucho olor, introducido poco antes en los jardines ingleses desde Sicilia (Blaringhem, 1919). Sus métodos, también rigurosos, eran completamente distintos a los de Mendel, y le permitieron crear métodos estadísticos (nada menos que los de "correlación" y de "regresión") y conceptos genéticos (el de heredabilidad está sugerido) de aplicación hoy en día en cualquier ciencia y llegar con ellos a otra explicación de la herencia de gran aplicación en selección de razas y variedades; a comienzos del XX se demostró que no solo no era incompatible con la teoría mendeliana sino que se podía explicar con esta última (Keynes, Edwards y Peel, 2005; Cubero, 2013).

Como complemento de los dos estudios fundacionales citados, valgan otros tres: el concepto de "línea pura", el primer "QTL" y la demostración de la replicación conservadora del ADN.

La obtención de nuevas variedades se hacía ya en el siglo XIX con arreglo a criterios científicos, aunque todavía no genéticos; desde mediado el siglo, la casa Vilmorin había diseñado un nuevo sistema de selección en remolacha azucarera, eligiendo las plantas no por su propio valor sino por el de sus descendientes (el método se denomina, con razón, evaluación de descendencia y se utiliza en casi todos los programas de mejora clásica); el éxito fue rotundo, pero había fracasado con el trigo: no se conseguía aumento alguno de rendimiento. Desde finales de ese mismo siglo, Wilhelm Johannsen, trabajando con una variedad de judía común, que se reproduce en autogamia estricta, sem- 
bró semillas asiladas de un lote comercial: las más pesadas dieron descendientes con semillas pesadas y las más ligeras plantas con semillas ligeras; pero ahí se acababa la selección: las segunda generación de cada tipo dio plantas con semillas de ese mismo tipo y así indefinidamente; cada línea originada en dichas plantas mantenía tenazmente generación tras generación el promedio del peso de sus semillas, sin que eligiendo las más grandes o las más pequeñas tal peso aumentara o descendiera en la descendencia. Johannsen las llamó líneas puras, y no solo tipificó el método de obtenerlas que aún se sigue en la actualidad, sino que intervino en el debate "transformista" de la época al demostrar que hay componentes fijos en la estructura de las especies. No pudo basarse en los trabajos de Mendel, recién "redescubiertos", pues sus resultados los publicó en 1903 tras los experimentos llevados a cabo durante años anteriores (y repetidos y publicados en 1926), si bien son fácilmente explicables por el mecanismo mendeliano de la herencia: las plantas de una población estrictamente autógama (como la de la judía) son homocigóticas (palabra que en 1903 no estaba creada), es decir, genéticamente idénticas entre sí, y así son sus descendientes mientras se sigan manteniendo en autofecundación; las diferencias en el peso dentro de cada planta son puros efectos ambientales (Srb et al., 1968). Tampoco tardaron mucho tiempo en integrarse en las teorías llamadas "sintéticas" de la evolución que fusionaron todas las aportaciones en el campo de la herencia sobre la base de la Genética (palabra creada en 1905) mendeliana y de la selección darwiniana (Cubero, 2013).

El primer estudio que mostró "asociación" de un carácter cuantitativo con otro cualitativo (un "marcador") es el de Sax en 1923 con judías. Cruzó una línea con semillas coloreadas grandes con otra de semillas blancas y pequeñas (el color en el grano es dominante sobre blanco). Las plantas $F_{2}$ se clasificaron atendiendo a su segregación en $\mathrm{F}_{3}$ para el color, con el resultado de que, asociado al alelo para el color se registró un incremento significativo del tamaño del grano. La interpretación alternativa, una acción pleiotrópica de dicho alelo, la refutó Rasmusson en 1935 con guisantes (otra vez una leguminosa...); cruzó una variedad tardía de flores coloreadas con otra precoz de flores blancas. Entre los descendientes se escogieron dos líneas, una de flor coloreada pero precoz y otra tardía y de flor blanca (es decir, recombinantes), que segregaron ahora plantas de flor coloreada y tardías y plantas de flor blanca y precoces, o sea, justamente lo contrario de lo obtenido en el primer cruzamiento, como debe ser si ha existido recombinación entre el gen responsable del color de la flor y la región donde se ubica el carácter cuantitativo de precocidad. El desarrollo de los modernos QTL por métodos moleculares es reciente, y quizá muchos ignoren los precedentes con dos especies modestas (Cubero, 2013).

Cuando en 1957 Taylor y colaboradores publicaron su estudio aun no existía una prueba de que el ADN se replicara como sugería el modelo de Watson y Crick. Taylor utilizó una leguminosa, pariente próximo de guisantes tanto del común como del "de olor": las habas. ¿Por qué...? Pues porque sus cromosomas eran material de investigación en citogenética por su tamaño, número y facilidad de tinción. Marcó con timidina radiactiva los cromosomas, observó la mitosis por autorradiografía y al microscopio y el resultado es bien conocido: el punteado de la timidina tritiada demostraba la hipótesis de la duplicación semiconservadora de una manera elegante y sin paliativos (Sánchez-Monge Parellada, 1972).

\section{EPÍLOGO}

Baste lo anterior para percibir lo cerca que, en el campo, en el bosque, en la mesa, en las creencias, en las costumbres, en el habla popular... y en la Ciencia hemos tenido unas compañeras inseparables. Como pago, la investigación moderna debería invertir algo más en ellas; su papel de "carne o pan del pobre" está muy lejos de haber terminado, teniendo en cuenta que, para el año 2050 , se estima que vamos a ser nueve mil millones de habitantes en este mundo, la mayor parte en países subdesarrollados (la expresión "en vías de desarrollo" es un eufemismo en la mayor parte de los casos), sin carne, casi sin pan, con tierras poco o nada fértiles, con la necesidad añadida de mantener un ambiente limpio sin contaminantes... Vale la pena, pues, ayudarlas un poco: bien han demostrado en el pasado que por poco que se les dio, devolvieron ciento por uno. 


\section{BIBLIOGRAFÍA}

Blaringhem, L. (1919). Les problemas de l'Hérédité expérimentale. Paris: Ernest Flammarion, Éditeur.

Cubero, J. I. (2013). Introducción a la Mejora Genética Vegetal (3.a ed.). Madrid: Paraninfo/Mundi Prensa.

Cubero, J. I. (2016, en prensa). Historia General de la Agricultura. Córdoba: Almuzara.

Cubero, J. I. y Moreno, M. T. (eds.) (1983). Leguminosas de grano. Madrid: MundiPrensa.

Darby, W. J., Ghalioungui, P. y Grivetti, L. (1977). Food: the gift of Osiris. Londres: Academic Press.

de Haro, A. (1983). La calidad nutritiva de las leguminosas de grano y su control genético. En Cubero, J. I, y Moreno, M. T. (eds.) Leguminosas de grano. Madrid: MundiPrensa, pp. 211-247.

Srb, A. M., Owen, R. D. y Edgar, R. S. (1968). Genética general. Barcelona: Ediciones Omega.
Font Quer, P. (1962). Plantas medicinales: el Dioscórides renovado. Barcelona: Labor.

Keynes, M., Edwards, A. W. F. y Peel, R. (eds.) (2005). A Century of Mendelism in Human Genetics. Londres: The Galton Institute / CRC Press.

Nadal, S., Moreno, M. T. y Cubero, J. I. (2004). Las leguminosas grano en la agricultura moderna. Madrid: MundiPrensa.

Orive R. y Temprano, F. (1983). Simbiosis Rhizobium-leguminosa. En Cubero, J. I. y Moreno, M.T. (eds.) Leguminosas de grano. Madrid: MundiPrensa, pp. 69-94.

Pérez de la Vega, M., Torres, A. M., Cubero, J. I. y Kole, Ch. (eds.) (2012). Genetics, Genomics and Breeding of Cool Season Grain Legumes. Enfield, N.H., USA: CRC Press.

Polhill, R. M. y Raven, P. H. (1981). Advances in Legume Systematics. Kew, Inglaterra: Royal Botanical Garden.

Sánchez-Monge Parellada, E. (1972). Genética (4.a ed). Madrid: Labor. 